\title{
IoT based Power Theft Detection
}

\author{
R Giridhar Balakrishna \\ Department of Electrical and Electronics Engineering \\ $V$ R Siddhartha Engineering College, Vijayawada, India \\ P Yogananda Reddy \\ Department of Electrical and Electronics Engineering \\ $V$ R Siddhartha Engineering College, Vijayawada, India \\ M L N Vital \\ Department of Electrical and Electronics Engineering \\ $V R$ Siddhartha Engineering College, Vijayawada, India
}

\begin{abstract}
Electrical power theft is a major problem in power system network all over the world, which is illegal and should be strictly prohibited. Power theft can be defined as the usage of the electrical power without any contract with the supplier. In order to eliminate power theft, the location of power theft is to be known so that appropriate action will be taken on the legal offenders.

The circuit consists of Arduino, GSM, LCD, ESP module and Current transformers. Meters cannot be used for high currents so current sensing is done by current transformers. Two CTs are used, one is connected at load side to measure the current through load and other C.T is connected at supply terminals to measure the current supplied by source. Using IoT, power theft detector kit has been implemented and the same also done using GSM for the purpose of backup protection.
\end{abstract}

Keywords- Power Theft, Arduino, IoT and ESP module.

\section{INTRODUCTION}

Generation, transmission and distribution of electrical energy involve many operational losses. Whereas losses implicated in generation can be technically defined, but transmission and distribution losses cannot be precisely quantified with the sending end information. This illustrates the involvement of nontechnical parameter in transmission and distribution of electricity. Overall technical losses occur naturally and are caused because of power dissipation in transmission lines, transformers, and other power system components. Technical losses in Transmission \&Distribution are computed with the information about total load and the total energy bill. While technology in the raising slopes, we should also note the increasing immoral activities. With a technical view, Power Theft is a non-ignorable crime and at the same time it directly affected the economy of a nation. Electricity theft a social evil, so it has to be completely eliminated. Power consumption and losses have to be closely monitored so that the generated power is utilized in a most efficient manner. The system prevents the illegal usage of electricity. At this point of technological development the problem of illegal usage of electricity can be solved without any human control using GSM and IoT.

The implementation of this system will save large amount of electricity, and there by electricity will be available for more number of consumer then earlier, in highly populated country such as India, China. Power theft can be defined as the usage of the electrical power without any legal contract with the supplier.

\section{PROPOSED METHOD}

In the society it was seen lot of people doing illegal power theft like unauthorized tapings from lines during functions and meter bypassing etc. these led us to do something to stop power theft as much as we can that is so why we choose "power theft detection" as a main project. IoT is the recently evolving technology.

Energy, particularly electricity, is a key input for accelerating economic growth. The theft of electricity is a criminal offence and power utilities are losing billions of rupees in this account. World losses US\$89.3 billion annually to 
electricity theft. The highest losses were in India ( $\$ 16.2$ billion), followed by Brazil ( $\$ 10.5$ billion) and Russia ( $\$ 5.1$ billion).

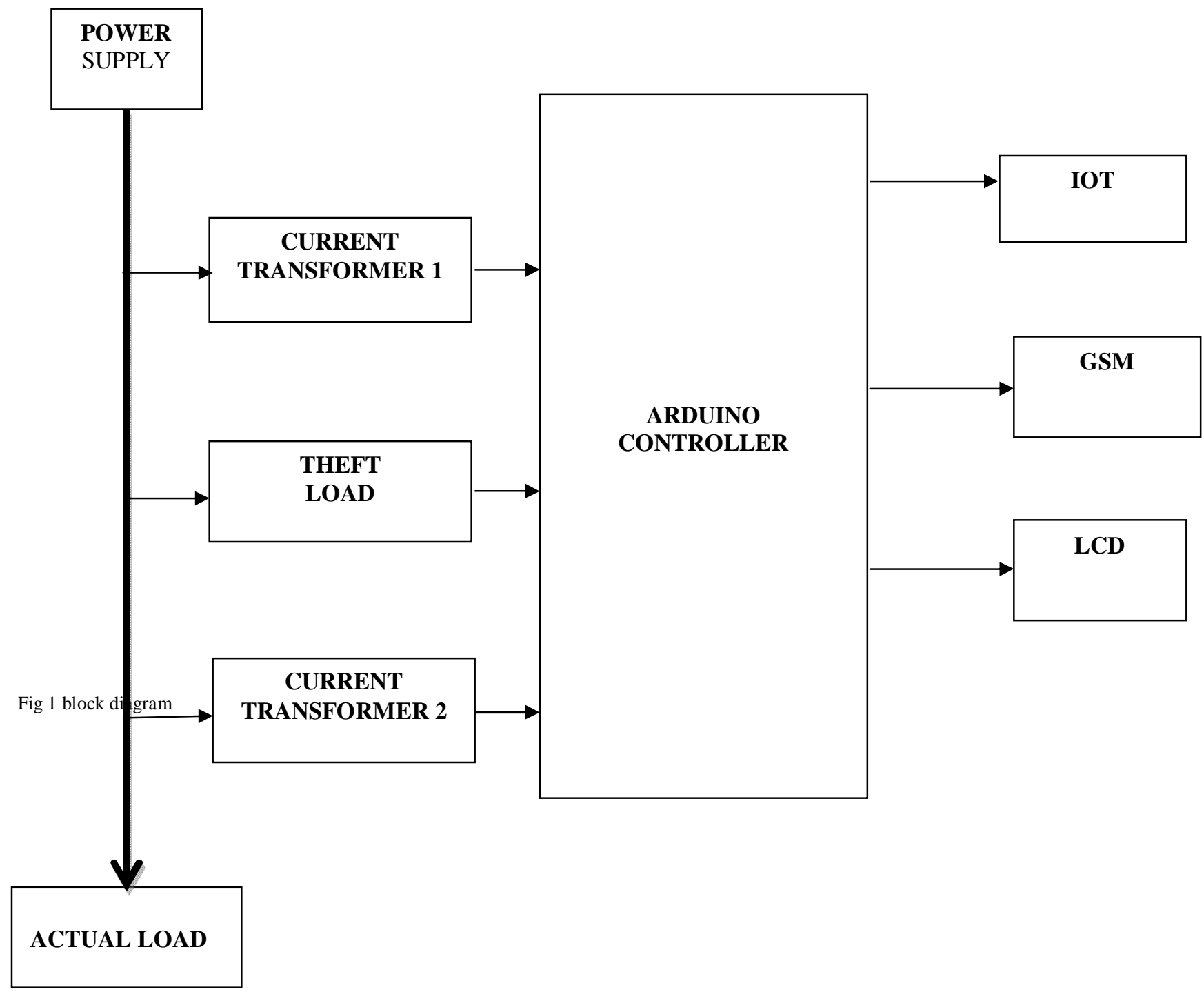

\section{OPERATION}

The circuit consists of Arduino, GSM, LCD, ESP module and Current transformers.Meters cannot be used for high currents so current sensing is done by current transformers. Two CTs are used, one is connected at load side to measure the current through load and other C.T is connected at supply terminals to measure the current supplied by source.

The main component in this circuit is Arduino controller.It receives current signal from two current transformers by the means of bridge rectifier. Then it compares those two current magnitudes by the conditional operator. Since there is no theft load, the two C.T.s shows almost the same values. Here the system is in healthy condition.

The Arduino cannot access current signal. So we have to interface the C.T. by means of voltage only. Here we have to convert the current signal into voltage signal. It can be converted by placing a resistor in series and taking voltage across the resistor and passing that voltage signal to arduino. Resistor is used because the secondary of current transformer should never be open circuited. The corresponding current can be obtained by doing calibration. Calibration can be done by connecting various loads and measuring different voltages and currents respectively. 
We can also convert current signal to voltage signal by using a rectifier. As the rectifier converts AC signal to DC signal, the output across the resistor connected in the rectifier circuit can be taken as the voltage signal. The secondary of the C.T is connected to the input of bridge rectifier. Capacitor is used to reduce the ripple content in the output. A resistor is connected at the output side to measure the voltage across it.

This voltage signal is given to the Arduino and the corresponding current can be calculated by the calibration. Thus the current signal from the C.T converted to the voltage signal for the purpose of access to the Arduino controller.

The same above procedure is also repeated for the C.T. connected at the load side. Program is written for accessing the voltage signals from the rectifier circuits. Condition is specified in the program for comparing the voltage magnitudes. If the variation is more than the specified value, that means the condition is violated. Then the control moves to the alert functions namely sms and twitter.

If any tapping is done, i.e, power theft is happened. Then two transformers shows different values. The source current is more than the actual load current. If there is any deviation more than the specified value then controller sends the signal to LCD, GSM and Internet of things.

The GSM is used for sending text message to the substation members by placing their mobile number in the code. IoT is used for sending tweet to the officials through internet.

LCD is used for the purpose of display. It shows the status of the load current and source current and also the amount of current that is deviated. GSM module will sends the text message to authority / person whose mobile number is given in the program according to the signal given by the Arduino controller. The Esp module allows an Arduino board to connect to the internet, so that the people in the substation can know the information about the power theft through internet and allowing them to take appropriate action against the offenders.

\section{A. ADVANTAGES:}

1) Security is automated.

2) Economy of country is saved.

3) Alert can be generated through GSM even in the case of failure of internet.

4) Does not affect the power transfer capability of line.

\section{B. APPLICATIONS:}

1) Used in distribution system.

2) Can be used in AMR

\section{HARDWARE DESCRIPTION}

The following components are used for making the proposed prototype:

\section{COMPONENTS USED:}

1) Arduino UNO

2) ESP8266

3) GSM module

4) Liquid crystal display

5) Current transformer

6) Bridge rectifier

7) Voltage Regulator (LM1117)

8) Voltage divider

9) Lamp load

10) Resistor

11) Capacitor 


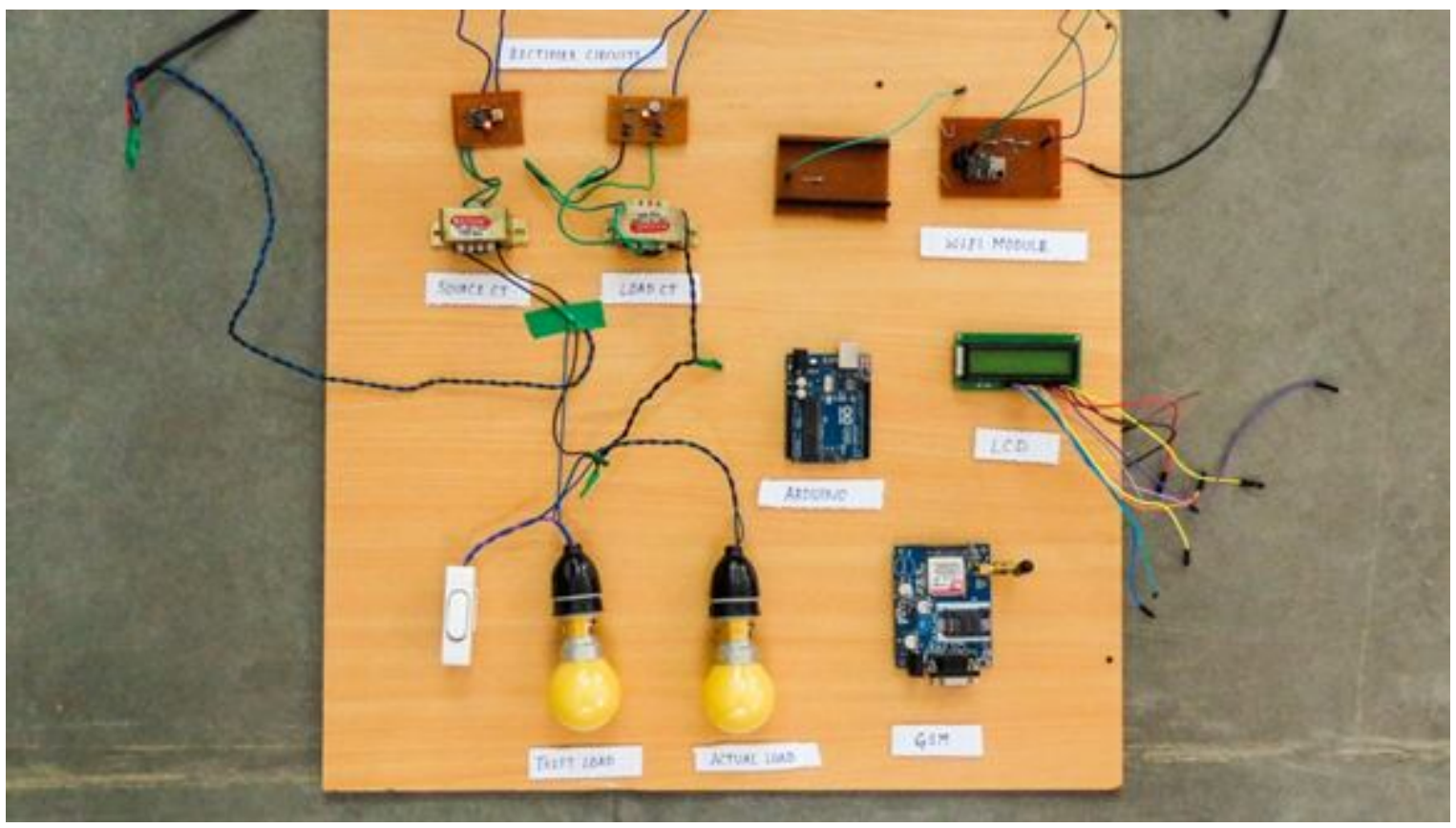

Fig. 2 Hardware proto type

Below, it is provided a glossary defining the Internet of Things:

- Internet of Things: A network of internet-connected objects able to collect and exchange data using embedded sensors.

- Internet of Things device: Any stand-alone internet-connected device that can be monitored and/or controlled from a remote location.

- Internet of Things ecosystem: All the components that enable businesses, governments, and consumers to connect to their IoT devices, including remotes, dashboards, networks, gateways, analytics, data storage, and security.

- $\quad$ Entity: Includes businesses, governments, and consumers.

- $\quad$ Physical layer: The hardware that makes an IoT device, including sensors and networking gear.

- $\quad$ Network layer: Responsible for transmitting the data collected by the physical layer to different devices.

- Application layer: This includes the protocols and interfaces that devices use to identify and communicate with each other.

- $\quad$ Remotes: Enable entities that utilize IoT devices to connect with and control them using a dashboard, such as a mobile application. They include smartphones, tablets, PCs, smartwatches, connected TVs, and nontraditional remotes.

- Dashboard: Displays information about the IoT ecosystem to users and enables them to control their IoT ecosystem. It is generally housed on a remote.

- $\quad$ Analytics: Software systems that analyze the data generated by IoT devices. The analysis can be used for a variety of scenarios, such as predictive maintenance.

- $\quad$ Data storage: Where data from IoT devices is stored.

- Networks: The internet communication layer that enables the entity to communicate with their device, and sometimes enables devices to communicate with each other.

\section{CONCLUSION}

Using IoT, power theft detector kit has been implemented and the same also done using GSM for the purpose of backup protection. In case of internet failure the alert will be made through text message.By using above 


\section{International Journal of Innovations in Engineering and Technology (IJIET) \\ http://dx.doi.org/10.21172/ijiet.83.016}

GSM and IoT techniques the crime of stealing power may be brought to an end, thereby a new bloom may be expected in the economy of our motherland and also there will be less scarcity for power utilisation.

\section{A. FUTURE SCOPE:}

As a further implementation to the developed model we can assemble GPS module in order to identify exact location power theft thereby identifying power theft at an ease.

\section{REFERENCES}

[1]. C. J. Bandim, E. R. Alves ., A. V. Pinto, F. C. Souza, M. R. B. Loureiro, C. A. Magalhges and F. Galvez-Durand, "Identification of Energy Theft and Tampered Meters Using a Central Observer Meter: A Mathematical Approach", Transmission and distribution conference and exposition, 2003 IEEE PES, vol. 1, pp. 163-168,2003.

[2]. H. Sundmaeker, P. Guillemin, P. Friess, S. Woelfflé, Vision and challenges for realising the Internet of Things, Cluster of European Research Projects on the Internet of Things - CERP IoT, 2010.

[3]. R.V. Kulkarni, A. Förster, G.K. Venayagamoorthy, Computational Intelligence in Wireless Sensor Networks: A Survey, IEEE Communications Surveys \& Tutorials. 13 (2011) 68-96.

[4]. "People Who Steal Edison's Electricity". Daily Yellowstone journal. March 27, 1886. Retrieved 2016-07-09. 